\title{
Lidil
}

Revue de linguistique et de didactique des langues

$64 \mid 2021$

Le passif dans la langue parlée

Francesco La Mantia, Pour se faire langage. Lexique élémentaire de la Théorie des opérations prédicatives et énonciatives d'Antoine Culioli

Louvain-la-Neuve, Academia-L'Harmattan, 2020, 276 p.

\section{Samia Ounoughi}

\section{OpenEdition}

Journals

Édition électronique

URL : https://journals.openedition.org/lidil/9458

DOI : $10.4000 /$ lidil. 9458

ISSN : $1960-6052$

Éditeur

UGA Éditions/Université Grenoble Alpes

Édition imprimée

ISBN : 978-2-37747-315-1

ISSN : $1146-6480$

Référence électronique

Samia Ounoughi, «Francesco La Mantia, Pour se faire langage. Lexique élémentaire de la Théorie des opérations prédicatives et énonciatives d'Antoine Culioli », Lidil [En ligne], 64 | 2021, mis en ligne le 01 novembre 2021, consulté le 25 novembre 2021. URL : http://journals.openedition.org/lidil/9458 ; DOI : https://doi.org/10.4000/lidil.9458

Ce document a été généré automatiquement le 25 novembre 2021.

(c) Lidil 


\title{
Francesco La Mantia, Pour se faire
} langage. Lexique élémentaire de la Théorie des opérations prédicatives et énonciatives d'Antoine Culioli

\author{
Louvain-la-Neuve, Academia-L'Harmattan, 2020, 276 p.
}

\section{Samia Ounoughi}

\section{RÉFÉRENCE}

Francesco La Mantia, Pour se faire langage. Lexique élémentaire de la Théorie des opérations prédicatives et énonciatives d'Antoine Culioli, Louvain-la-Neuve, Academia-L'Harmattan, 2020,276 p.

1 Professeur associé de philosophie du langage à l'Université de Palermo, Francesco La Mantia nous présente un glossaire des concepts-clés de la TOPE (Théorie des opérations prédicatives et énonciatives) que l'on doit à Antoine Culioli (1924-2018). Cet ouvrage est de composition hétérogène, car au-delà du glossaire non exhaustif de termes-clés de la TOPE, il comporte une introduction conséquente à la structure "en came", un entretien avec Antoine Culioli mené en collaboration avec Sophie Fisher (professeure de linguistique à l'EHESS) et une postface également co-écrite avec elle.

2 Avant de commencer le glossaire, Francesco La Mantia se lance dans la démarche ardue d'explicitation de la structure en came, qui est un terme emprunté à la mécanique et qui décrit un mécanisme complexe de transformation des mouvements. Plus dessinée que définie verbalement par Antoine Culioli, la structure en came est pourtant fondamentale, dans la mesure où le père de la TOPE s'en sert pour proposer un diagramme du travail énonciatif qui s'opère à partir de la lexis. La came expose donc la manière dont s'ordonnent les mouvements divers et simultanés qui s'opèrent à partir 
des composants sémantiques de ce qui pourrait potentiellement être énoncé (la lexis) pour arriver à la production de langage. Ce tracé, loin de se limiter à une tentative de représentation figurale du travail énonciatif, décrit aussi le travail métalinguistique à l'œuvre dans l'émergence de l'énoncé encore en devenir. À la came dans laquelle le figural et le métalinguistique coexistent et se complètent s'ajoute la bifurcation, un autre type de diagramme qui représente les possibilités de décisions assertives (par exemple, positive ou négative) qui se déploient avant la production de l'énoncé.

3 La seconde partie de l'ouvrage est consacrée à un glossaire contenant 58 entrées avec quelques sous-entrées. Il est fondé à l'appui d'un corpus de textes de Culioli lui-même et de certains des principaux spécialistes de la TOPE (Sophie Fisher, JeanJacques Franckel, etc.). Le glossaire regroupe surtout les termes à forts enjeux métalinguistiques et épilinguistiques. Les définitions sont complétées par des diagrammes, des citations d'Antoine Culioli et des références bibliographiques. Enfin, l'entretien que Francesco La Mantia a co-mené avec Sophie Fisher offre la possibilité de reprendre certains des termes du glossaire pour les éclaircir à partir de cet échange direct avec le père de la TOPE.

4 Francesco La Mantia ne vise pas l'exhaustivité, mais il souhaite avant tout éclaircir la démarche d'Antoine Culioli tout en mettant en évidence les vides, les manques, les failles, voire les flous dans les explications de cette démarche intellectuelle complexe. Les diverses parties de son ouvrage font intervenir de l'oral retranscrit aussi bien que des textes écrits, qui se font écho et se complètent. Elles permettent aussi de saisir un peu mieux la TOPE à différentes échelles. L'une, très conceptuelle, ramène aux questionnements philosophiques premiers qui ont catalysé la recherche d'Antoine Culioli et l'autre, plus technique, tente de modéliser le travail complexe dont résulte chacun de nos énoncés.

5 Cet ouvrage s'adresse à des publics différents, car il est de composition (volontairement) hétérogène. Les linguistes spécialisés dans la recherche sur la TOPE et plus largement dans les théories de la linguistique apprécieront l'exposé sur la structure en came qui ouvre ce livre et dont il est rarement question ailleurs. La méthodologie y est aussi rigoureuse que prudente, tant l'auteur aura dû composer avec les silences d'Antoine Culioli. Cette partie sera donc difficilement accessible à un public non spécialiste. Le glossaire, quant à lui, sera fort utile aux étudiants en langues et en sciences du langage ainsi qu'aux enseignants dans ces disciplines. Enfin, pour les admirateurs d'Antoine Culioli, cet ouvrage sera un plaisir à découvrir, car l'auteur y dit sans ambages son admiration pour le père de la TOPE qui fut son professeur et inspira sa carrière.

\section{AUTEURS}

\section{SAMIA OUNOUGHI}

Univ. Grenoble Alpes, LIDILEM, 38000 Grenoble, France 